\title{
IDENTIFIKASI SIDIK JARI DENGAN MENGGUNAKAN STRUKTUR MINUTIA
}

\author{
Anggya N.D. Soetarmono, S.Kom. ${ }^{*}$ \\ ABSTRAK
}

Penelitian ini membahas tentang sistem identifikasi personal dengan menggunakan kesesuaian biometrik pada pola sidik jari. Sesuai atau tidak sesuainya sebuah sidik jari dapat diketahui setelah melampaui serangkaian proses. Dimulai dari akuisisi citra sidik jari, memperbaiki kualitas citra, kemudian menggali fitur-fitur minutia yang ada pada citra sidik jari, hingga akhirnya dapat diukur nilai kesesuaiannya. Minutiae based matching adalah metode yang dipilih untuk mengukur tingkat kesesuaian pola sidik jari karena metode ini diyakini akan memberikan tingkat akurasi yang lebih baik jika dibandingkan dengan metode pattern based matching yang mana pada metode tersebut hanya membandingkan citra dari dua buah sidik jari.

Kata Kunci: sidik jari, minutiae, biometrik

\section{PENDAHULUAN}

Identifikasi dengan menggunakan pola sidik jari merupakan teknik biometrik yang tertua di dunia. Sejarahnya kembali ke zaman 6000 tahun sebelum masehi. Penggunaan sidik jari sebagai kode personal, memiliki tradisi yang panjang dan telah digunakan oleh bangsa Assyiria, Babylonia, Jepang dan Cina. Sejak tahun 1897, dactyloscopy (sinonim dari identifikasi sidik jari tanpa komputer) telah digunakan untuk identifikasi kejahatan, karena karakteristik sidik jari dari setiap orang adalah unik dan secara normal tidak berubah selama hidupnya.

\subsection{Latar Belakang}

Sidik jari manusia merupakan bukti materi yang amat penting. Tak ada sidik jari yang identik di dunia ini sekalipun di antara dua saudara kembar. Dalam dunia sains pernah dikemukakan, jika ada 5 juta orang di bumi, kemungkinan munculnya dua sidik jari manusia yang sama baru akan terjadi lagi 300 tahun kemudian. Untuk membandingkan sidik jari satu dengan yang lain digunakan suatu metode yang bernama Minutiae Based Matching. Minutiae atau minutia adalah guratan-guratan yang terdapat pada kulit jari di tangan manusia, minutia inilah yang membentuk pola sidik jari. Minutia memiliki jenis yang berbeda-beda, dimana jumlah dan bentuk minutia akan menjadi fitur penting yang diuji untuk mendapatkan kesesuaian pola sidik jari.

\subsection{Perumusan Masalah}

Minutia memiliki berbagai macam bentuk, namun yang digunakan dalam metode Minutiae Based Matching adalah bentuk Ridge Ending dan Bifurcation, fitur yang harus digali dari 2 bentuk minutia diatas adalah posisi koordinat relatif dan sudut kemiringan minutia. Maka, masalah yang timbul dalam pemanfaatan Minutiae Based Matching adalah:

\footnotetext{
* Staf Pengajar Program Studi S1-Sistem Informasi IKADO
} 
a. Bagaimana cara menemukan pola/bentuk Ridge Ending dan Bifurcation pada citra sidik jari?

b. Bagaimana melakukan ekstraksi fitur pada setiap Ridge Ending dan Bifurcation?

c. Bagaimana cara membandingkan 2 data minutia?

\subsection{Tujuan dan Manfaat Penelitian}

Tujuan dari penelitian ini adalah mempelajari teknik Minutiae Based Matching dan semua proses pendukungnya mulai dari akuisisi citra hingga klasifikasi fitur sehingga dari penelitian ini sidik jari dapat dimanfaatkan sebagai identitas individu dengan tingkat akurasi yang tinggi.

\section{LANDASAN TEORI}

Landasan teori yang digunakan pada penelitian ini adalah pengolahan citra digital dan Minutiae, pada bagian ini akan dipaparkan sehingga minutia pada sidik jari dapat dimanfaatkan sebagai identitas individu.

\subsection{Minutia (Minutiae)}

Berasal dari bahasa latin "minutus" yang berarti kecil, minutia adalah perpotongan guratan-guratan(ridge) kulit yang membentuk sidik jari manusia. Minutia terdapat dalam berbagai macam pola/bentuk

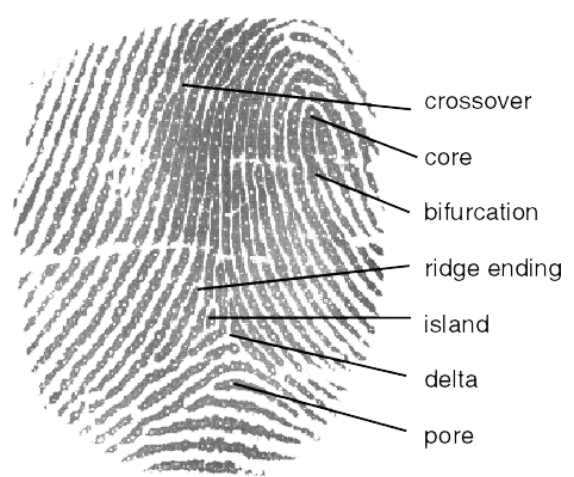

Gambar bentuk-bentuk minutia

- Crossover, perpotongan yang menyerupai huruf X

- Bifurcation, percabangan sebuah ridge

- Ridge Ending, akhir dari sebuah ridge

- Island, small ridge atau sebuah guratan pendek yang tidak bercabang, tidak memiliki lengkungan dalam, atau pun perpotongan.

- Core, titik terdalam pada sebuah lengkungan ridge

- Delta, titik dimana terdapat perpotongan dari tiga buah ridge 


\subsection{Minutiae Based Matching}

Metode ini memanfaatkan titik-titik minutia sebagai bahan perbandingan, ada dua macam bentuk minutia yang digunakan sebagai referensi, meskipun terdapat bermacam-macam bentuk minutia yang lain.

a. Ridge Ending

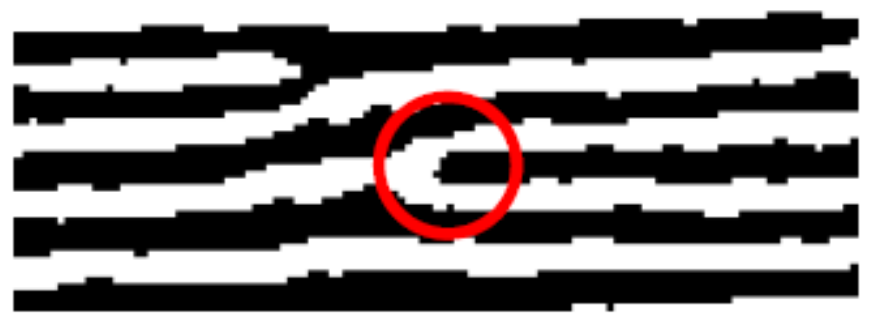

Gambar minutia tipe ridge ending

Ridge ending adalah akhir dari sebuah ridge atau sebuah ridge yang terputus menjadi dua. Namun tidak semua ridge yang terputus adalah sebuah ridge ending.

\section{b. Bifurcation}

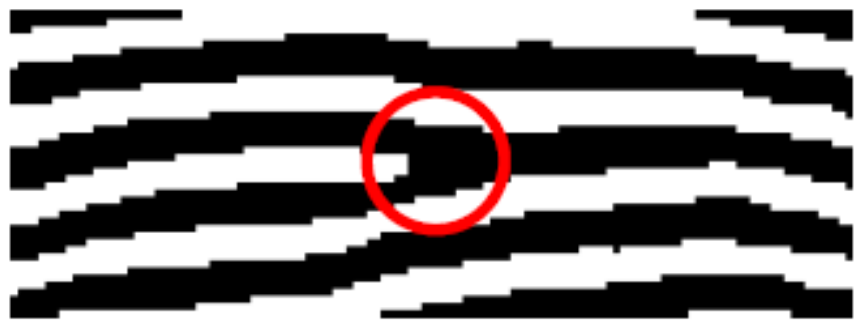

Gambar minutia tipe bifurcation

Bifurcation adalah percabangan dari sebuah ridge.

Pada metode Minutia based matching yang digunakan sebagai fitur pembanding adalah tipe minutia, posisi koordinat relatif minutia, dan sudut kemiringan minutia. Metode ini dipandang lebih fleksibel dibandingkan pattern based matching, karena tetap dapat bekerja secara optimal apabila sebagian dari sidik jari terluka atau terkelupas.

\section{Metode Penelitian}

Agar sidik jari dapat digunakan sebagai identitas maka harus dilakukan beberapa langkah berikut ini :

- Akuisis citra sidik jari (Image Acquisition)

- Perbaikan citra sidik jari (Image Enhancement)

- Ekstraksi fitur (Feature Extraction)

- Pencocokan sidik jari (Matching) 
Sub berikutnya akan menjelaskan setiap langkah yang harus ditempuh dalam peneletian ini.

\subsection{Akuisis Citra Sidik Jari}

Proses akuisisi citra digital dari sidik jari seseorang memerlukan sebuah alat “fingerprint scanner". Dengan bantuan alat ini maka citra digital dari sebuah sidik jari dengan mudah didapatkan.
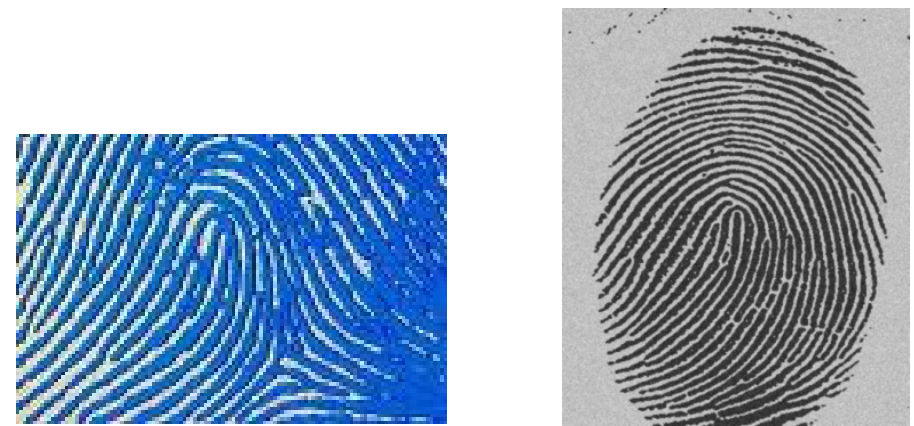

Citra digital sidik jari hasil akuisisi dari fingerprint scanner

Gambar diatas menunjukan dua buah citra sidik jari yang dihasilkan dari dua buah fingerprint scanner yang berbeda. Dengan demikian maka kualitas citra digital yang dihasilkan bergantung pada fingerprint scanner-nya.

\subsection{Perbaikan Citra Sidik Jari}

Perbaikan (Enhancement) yang dilakukan pada citra sidik jari yang akan di proses adalah melakukan thresholding, yaitu melakukan pemisahan antara gambar objek sidik jari dengan gambar latar belakang. Metode thresholding yang digunakan adalah metode distributif, metode ini memanfaatkan histogram untuk melihat sebaran pixel gambar. pixel dengan nilai histogram tertinggi akan dianggap sebagai gambar latar yang harus dibuang, dan nilai rendah akan dianggap sebagai gambar objek.

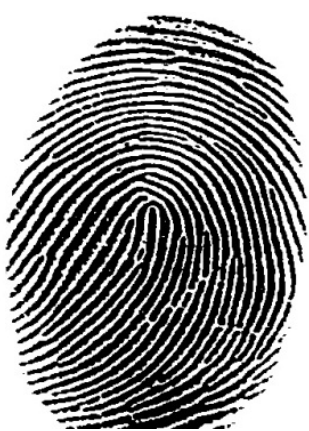

Citra digital sidik jari hasil thresholding

\subsection{Ekstraksi Fitur}

Pada proses ini dilakukan pencarian dimana titik-titik minutia berada, ekstraksi fitur terbagi menjadi empat bagian, yaitu : 
a. Estimasi arah pada citra sidik jari dilakukan dengan membagi (segmentasi) citra sidik jari menjadi blok-blok citra yang lebih kecil dengan ukuran yang sama. Setelah itu pada semua pixel di setiap blok dihitung gradiennya, dengan menggunakan rumus berikut ini.

$$
\theta=\frac{1}{2} \tan ^{-1}\left(\frac{\sum_{i=1}^{W} \sum_{j=1}^{W} 2 G_{x}(i, j) G_{y}(i, j)}{\sum_{i=1}^{W} \sum_{j=1}^{W}\left(G_{x}^{2}(i, j)-G_{y}^{2}(i, j)\right)}\right)
$$

Rumus Estimation Of Orientation Field

b. Pendeteksian guratan (Ridge Detection)

Setelah arah dari sidik jari diestimasikan pada proses diatas, maka proses pendeteksian guaratan (ridge) dilakukan dengan menggunakan teknik konvolusi pada citra sidik jari untuk melakukan perhitungan nilai graylevel dengan rumus :

$$
\begin{gathered}
h_{t}(x, t ; u, v)=\left\{\begin{array}{c}
-\frac{1}{\sqrt{2 \pi \delta}} e^{\frac{u}{\delta^{2}}}, \quad \text { if } u=\left(v \tan (\theta(x, y))-\frac{H}{2 \cos (\theta(x, y))}\right), v \in \Omega \\
\frac{1}{\sqrt{2 \pi \delta}} e^{\frac{u}{\delta^{2}}}, \text { if } u=(v \tan (\theta(x, y))), v \in \Omega \\
0, \text { otherwise }
\end{array}\right\} \\
h_{b}(x, t ; u, v)=\left\{\begin{array}{c}
-\frac{1}{\sqrt{2 \pi \delta}} e^{\frac{u}{\delta^{2}}}, \quad \text { if } u=\left(v \tan (\theta(x, y))-\frac{H}{2 \cos (\theta(x, y))}\right), v \in \Omega \\
\frac{1}{\sqrt{2 \pi \delta}} e^{\frac{u}{\delta^{2}}}, \text { if } u=(v \tan (\theta(x, y))), v \in \Omega \\
0, \text { otherwise }
\end{array}\right\}
\end{gathered}
$$

Dimana $\theta(\mathrm{x}, \mathrm{y})$ adalah arah kemiringan pada pixel koordinat $(\mathrm{x}, \mathrm{y})$ yang didapatkan dari proses sebelumnya, apabila nilai graylevel ht(x,y,u,v) dan $\mathrm{hb}(\mathrm{x}, \mathrm{y}, \mathrm{u}, \mathrm{v})$ lebih besar dari nilai threshold $\mathrm{T}$ yang ditentukan, maka pada titik tersebut ditandai sebagi ridge.

c. Pembentukan tulang (Skeletoning/Thinning)

Pada setiap pixel $r(i, j)$ yang ditandai sebagai guratan (ridge) dilakukan proses thinning dengan aturan :

1. Pada pixel $r(i, j)$ memiliki $2-6$ tetangga pixel ridge

2. Perubahan pixel tetangga antara pixel gambar latar dan gambar objek yang dalam hal ini adalah pixel ridge disekeliling $r(i, j)$ bernilai 1 .

3. Perkalian pixel tetangga atas, kanan, dan bawah bernilai 0

4. Pekalian pixel tetangga kanan, bawah dan kiri bernilai 0

5. Apabila syarat 1-4 terpenuhi maka tandai pixel tersebut.

6. Hapus pixel yang memiliki tanda.

7. Ulangi proses 1-6 tetapi pada proses 3, pixel tetangga yang di hitung adalah kiri, atas, dan kanan, sedangkan pada proses 4, pixel yang tetangga yang dihitung adalah kanan, bawah dan kiri.

Ulangi sampai tidak ada lagi pixel yang diberi tanda. 
d. Pendeteksian Minutia

Pendeteksian minutia dilakukan dengan konvolusi 8 tetangga, yang dicari adalah akhir dari sebuah ridge( ridge ending) dan percabangan sebuah ridge (bifurcation). Sebuah ridge didefinisikan sebagai ridge ending apabila sebuah pixel ridge $\mathrm{r}(\mathrm{i}, \mathrm{j})$ hanya memiliki 1 tetangga, sedangkan sebuah ridge didefinisikan sebagai percabangan atau bifurcation apabila pixel ridge $\mathrm{r}(\mathrm{i}, \mathrm{j})$ memiliki lebih dari 2 tetangga pixel. Namun untuk meningkatkan ketelitian dalam pendeteksian minutia maka ditambahkan beberapa aturan dalam pendeteksian minutia. Aturan-aturan tersebut adalah :

1. Apabila sebuah percabangan memiliki lebih dari 2 cabang dan panjangnya kurang dari batasan (threshold) yang ditentukan maka pixel tersebut tidak ditandai sebagai bifurcation.

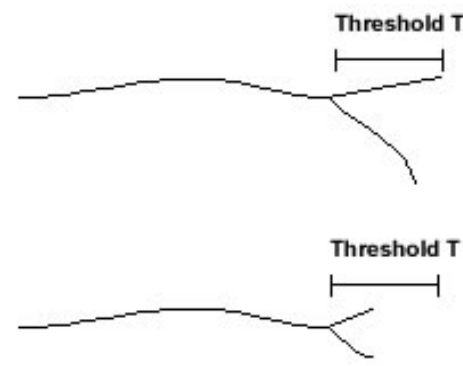

Gambar 3.4. Minutia tipe Bifurcation.

2. Apabila terdapat patahan yang pendek (jarak antara patahan dengan tetanga lainnya tidak lebih dari 1 pixel) maka pixel tersebut tidak ditandai sebagai ridge ending.

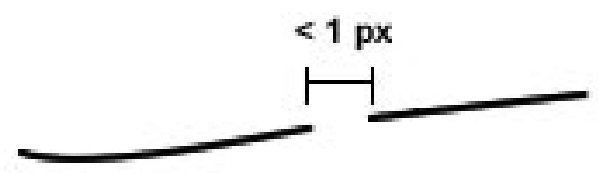

Minutia tipe ridge ending.

3. Apabila banyak minutia (bifurcation atau ending) ditemukan dalam satu daerah(cluster) yang berdekatan, maka hapus semua minutia tersebut, tapi sisakan satu minutia yang paling dekat dengan titik pusat dari daerah tersebut.

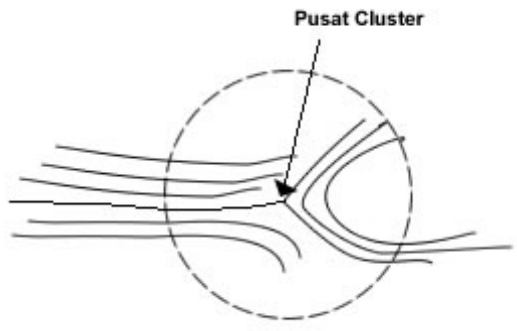

Bifurcation pada pusat cluster diambil sebagai minutia.

4. Apabila sebuah minutia ditemukan berhadapan, dan tidak ada guratan (ridge) yang membatasinya, maka hapus minutia tersebut. 


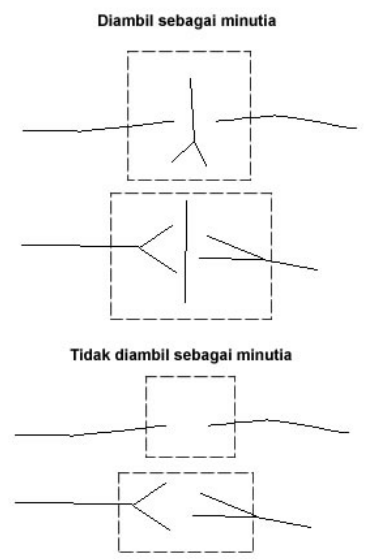

Setelah proses tersebut dilakukan maka dapat dilanjutkan dengan proses pemcocokan (matching).

\subsection{Pencocokan}

Secara sederhana pencocokan disidik jari dilakukan dengan membandingkan sidik jari yang ada dalam database (template) dengan sidik jari yang ditemukan (input minutia). Untuk menemukan pola yang cocok maka dilakukan tahapan. Yaitu :

a. Untuk melakukan pencocokan dari dua buah data sidik jari, maka sidik jari yang berasal dari template perlu disejajarkan dengan sidik jari inputan. Pada saat pencarian titik-titik minutia, ridge dimana minutia tersebut ditemukan,juga disimpan. Ridge tersebutlah yang nantinya akan disejajarkan, untuk mensejajarkan antara dua set ridge (template dan input) digunakan rumus berikut ini.

$$
S=\frac{\sum_{i=0}^{L} d_{i} D_{i}}{\sqrt{\sum_{i=0}^{L} d_{i}^{2} D_{i}^{2}}}
$$

Dimana $L$ adalah jarak minimal antara 2 ridge. $d_{i}$ dan $D_{i}$ adalah jarak antara disetiap pixel ridge $\mathrm{d}$ dan ridge $\mathrm{D}$ terhadap garis sumbu $\mathrm{x}$-absis. $\mathrm{d}$ adalah himpunan ridge input, sedangkan D adalah himpunan ridge template. Apabila nilai S yang didapatkan masih dalam batasan yang ditentukan (Threshold) maka lanjutkan pada langkah 2, jika nilai $\mathrm{S}$ berada dibawah nilai batas maka lakukan perhitungan kembali untuk pasangan ridges berikutnya.

b. Melakukan Rotasi terhadap pasangan minutia yang dihasilkan dari proses pertama dengan rumus :

$$
\left(\begin{array}{l}
\Delta x \\
\Delta y
\end{array}\right)=\left(\begin{array}{l}
x^{d} \\
y^{d}
\end{array}\right)-\left(\begin{array}{l}
x^{D} \\
y^{D}
\end{array}\right)
$$

Dimana $\left(\mathrm{x}^{\mathrm{d}}, \mathrm{y}^{\mathrm{d}}\right)^{\mathrm{T}}$ dan $\left(\mathrm{x}^{\mathrm{D}}, \mathrm{y}^{\mathrm{D}}\right)^{\mathrm{T}}$ adalah koordinat $\mathrm{x}$ dan $\mathrm{y}$ dari kedua minutia yang terdapat pada ridge d dan $\mathrm{D}$. Besar dari sudut rotasi dihitung dengan rumus:

$$
\Delta \theta=\frac{1}{L} \sum_{i=0}^{L}\left(\gamma_{i} \Gamma_{i}\right)
$$


Dimana L adalah jarak minimal antara dua ridge d dan $\mathrm{D}, \gamma_{\mathrm{i}}$ dan $\Gamma_{\mathrm{i}}$ adalah besarnya sudut radial pada pixel yang ke i pada ridge d dan $\mathrm{D}$.

c. Setelah proses 2 selesai maka didapatkan $\left(\mathrm{x}^{\mathrm{d}}, \mathrm{y}^{\mathrm{d}}, \theta^{\mathrm{d}}\right)^{\mathrm{T}}$ sebagai refresnsi untuk melakukan transformasi bagi titik minutia yang lain. Dilakukan translasi dan rotasi untuk semua minutia input yang dengan rumus :

$$
\left[\begin{array}{l}
x_{i}^{A} \\
y_{i}^{A} \\
\theta_{i}^{A}
\end{array}\right]=\left[\begin{array}{l}
\Delta x \\
\Delta y \\
\Delta \theta
\end{array}\right]+\left[\begin{array}{ccc}
\cos \Delta \theta & \sin \Delta \theta & 0 \\
\sin \Delta \theta & -\cos \Delta \theta & 0 \\
0 & 0 & 1
\end{array}\right]\left[\begin{array}{l}
x_{i}-x^{d} \\
y_{i}-y^{d} \\
\theta_{i}-\theta^{d}
\end{array}\right]
$$

Dimana $\left(\mathrm{x}_{\mathrm{i}}, \mathrm{y}_{\mathrm{i}}, \theta_{\mathrm{i}}\right)^{\mathrm{T}},(\mathrm{i}=1,2, \ldots \mathrm{N})$ adalah minutia dari sidik jari yang diinputkan, dan $\left(\mathrm{x}_{\mathrm{i}}^{\mathrm{A}}, \mathrm{y}_{\mathrm{i}}^{\mathrm{A}}, \theta_{\mathrm{i}}^{\mathrm{A}}\right)^{\mathrm{T}}$ adalah minutia referensi yang sudah sejajar dengan minutia template.

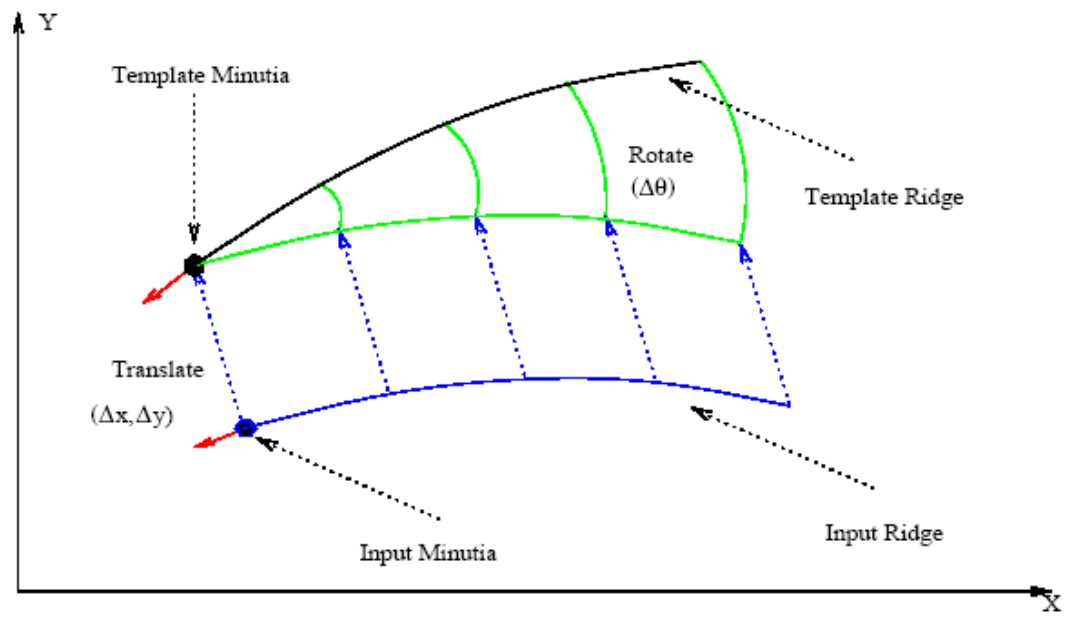

d. Setelah minutia-minutia dari kedua sidik jari tersebut di sejajarkan, maka selanjutnya merubah semua titik minutia ke dalam sebuah koordinat polar.

$$
\begin{aligned}
& P=\left(x_{1}^{P}, y_{1}^{P}, \theta_{1}^{P}\right)^{T}, \ldots,\left(x_{M}^{P}, y_{M}^{P}, \theta_{M}^{P}\right)^{T} \\
& Q=\left(x_{1}^{Q}, y_{1}^{Q}, \theta_{1}^{Q}\right)^{T}, \ldots,\left(x_{N}^{Q}, y_{N}^{Q}, \theta_{N}^{Q}\right)^{T}
\end{aligned}
$$

Dimana $\mathrm{P}$ adalah himpunan minutia template sejumlah $\mathrm{M}$ buah, Q adalah himpunan minutia yang diinputkan sejumlah $\mathrm{N}$ buah, hasil dari proses c. Dikomputasikan dengan rumus :

$$
\left[\begin{array}{c}
r_{i} \\
e_{i} \\
\theta_{i}
\end{array}\right]=\left[\begin{array}{c}
\sqrt{\left(x_{i}^{*}-x^{r}\right)^{2}+\left(y_{i}^{*}-y^{r}\right)^{2}} \\
\tan ^{-1}\left(\frac{y_{i}^{*}-y^{r}}{x_{i}^{*}-x^{r}}\right) \\
\theta_{i}^{*}-\theta^{r}
\end{array}\right]
$$

Dimana $\left(\mathrm{x}_{\mathrm{i}}{ }^{*}, \mathrm{y}_{\mathrm{i}}{ }^{*}, \theta_{\mathrm{i}}\right)^{\mathrm{T}}$ koordinat dari minutia, $\left(\mathrm{x}^{\mathrm{r}}, \mathrm{y}^{\mathrm{r}}, \theta^{\mathrm{r}}\right)^{\mathrm{T}}$ adalah koordinat dari minutia referensi. $\left(\mathrm{r}_{\mathrm{i}}, \mathrm{e}_{\mathrm{i}}, \theta_{\mathrm{i}}\right)^{\mathrm{T}}$ adalah representasi minutia dalam system koordinat polar, $\mathrm{r}_{\mathrm{i}}$ adalah representasi jarak radial, $\mathrm{e}_{\mathrm{i}}$ adalah representasi sudut radial, dan $\theta_{\mathrm{i}}$ adalah representasi arah orientasi minutia terhadap minutia referensi. Hasilnya adalah :

$$
P p=\left(\left(r_{1}^{P}, e_{1}^{P}, \theta_{1}^{P}\right)^{T}, \ldots,\left(r_{M}^{P}, e_{M}^{P}, \theta_{M}^{P}\right)^{T}\right)
$$




$$
Q p=\left(\left(r_{1}^{Q}, e_{1}^{Q}, \theta_{1}^{Q}\right)^{T}, \ldots,\left(r_{N}^{Q}, e_{N}^{Q}, \theta_{N}^{Q}\right)^{T}\right)
$$

Pp dan Qp adalah representasi koordinat minutia template dan input dalam bentuk system koordinat polar.

e. Untuk setiap P dan Q kemudian dihitung perbedaannya (distance) dan ditabelkan, dengan rumus :

$$
\begin{gathered}
\Delta d=r_{i}-r_{j} \\
\Delta \alpha=\operatorname{abs}\left(\theta_{i}-\theta_{j}\right)+\operatorname{abs}\left(e_{i}-e_{j}\right)
\end{gathered}
$$

Sehingga distance dari $\mathrm{P}_{\mathrm{i}}$ dan $\mathrm{Q}_{\mathrm{j}}$ adalah :

$$
\mathrm{D}\left(\mathrm{P}_{\mathrm{i}}, \mathrm{Q}_{\mathrm{j}}\right)=\Delta \mathrm{d}+\Delta \alpha
$$

Kemudian dilakukan pencarian pada tabel tersebut dengan aturan : pada setiap baris yang terbentuk, kecuali nilai 0, dapatkan nilai minimum dari baris tersebut, kemudian rubah semua nilai pada baris dan kolom dimana ditemukan nilai minimumnya menjadi 0 , kecuali nilai minimumnya. Jumlah minutia yang cocok adalah sejumlah ditemukannya nilai minimum. Untuk menghitung nilai kebenarannya digunakan rumus :

$$
R=\sqrt{\left(\frac{k^{2}}{m n}\right)}
$$

Dimana $\mathrm{R}$ adalah nilai kebenaran, $\mathrm{k}$ adalah jumlah pasangan minutia yang cocok, sedangkan $\mathrm{m}$ adalah jumlah minutia dari template dan $\mathrm{n}$ adalah jumlah minutia dari sidik jari input.

\section{Uji Coba}

Dengan memanfaatkan 5 data sidik jari untuk uji coba, maka didapatkan hasil sebagai berikut:

\begin{tabular}{|c|c|c|c|}
\hline Sample & Max. Minutia & Matching Rate & Time stamp \\
\hline 1 & 20 & $99,42 \%$ & 3,217 detik \\
\hline 2 & 22 & $99,39 \%$ & 3,238 detik \\
\hline 3 & 30 & $99,27 \%$ & 3,316 detik \\
\hline 4 & 36 & $99,20 \%$ & 3,352 detik \\
\hline 5 & 41 & 99.14 & 3.361 \\
\hline
\end{tabular}

\begin{tabular}{|l|c|l|}
\hline Sample & False Accept Rate & False Refuse Rate \\
\hline 1 & $5.0 \%$ & $0.8 \%$ \\
\hline 2 & $4.0 \%$ & $1.7 \%$ \\
\hline 3 & $3.0 \%$ & $1.8 \%$ \\
\hline 4 & $2.0 \%$ & $3.2 \%$ \\
\hline 5 & $1.0 \%$ & $5.6 \%$ \\
\hline
\end{tabular}




\section{Kesimpulan \& Saran}

Pada akhir dari penelitian ini, dapat ditarik beberapa kesimpulan dan saran yang dapat dilakukan dalam rangka mengembangkan hasil penelitian ini di kelak kemudian hari.

\subsection{Saran}

Dari penelitian ini maka dapat diambil beberapa kesimpulan:

- Tingkat keberhasilan proses ekstraksi minutia sangat bergantung pada kualitas citra dari sidik jari. Apabila citra yang didapatkan terlalu rendah kualitasnya atau memiliki banyak noise, maka sejumlah minutia tidak dapat ditemukan.

- Tingkat kecocokan dengan menggunakan Minutiae based matching untuk pencocokan sidik jari memiliki tingkat keakuratan yang sangat tinggi.

\subsection{Kesimpulan}

- Pada proses Minutiae matching, ridge dimana terdapat minutia referensi, akan disejajarkan. Dan minutia yang lain akan mengikuti. Namun akan lebih baik jika sidik jari tersebut dinormalisasi ukurannya. Hal ini dapat mengatasi perbedaan rentang waktu ketika sebuah contoh sidik jari diambil, misalnya seseorang diambil sidik jarinya pada usia 17 tahun saat membuat SIM, kemudian 50 tahun kemudian sidik jarinya diambil lagi. Bentuk minutianya tidak akan mengalami perubahan. Namun luasan sidik jari yang diambil akan mengalami penambahan akibat proses penuaan. Hal ini akan sangat mempengaruhi hasil pencocokan. Proses normalisasi akan membuat sebuah sidik jari akan menjadi elastis, dengan struktur sidik jari yang tidak berubah, namun ukuran panjang ridge-nya dapat disesuaikan. Dengan demikian perubahan luasan kulit dapat diatasi.

- Gabor Filters dapat digunakan sebagai alternatif dalam proses perbaikan citra, karena akan menghasilkan citra sidik jari yang lebih baik. namum penggunaan filter tersebut akan menambah waktu dalam pemrosesan citra sidik jari.

\section{Daftar Pustaka}

Anil Jain, Lin Hong, Sharath Pankanti_, and Ruud Bolle, ”An Identity Authentication System Using Fingerprints", Department of Computer Science Michigan State University. Michigan. 1997.

Anil Jain \& Lin Hong. "On - Line Fingerprint Test”. Pattren Recognition And Image Processing Laboratory, Department Of Computer Science Michigan State University. Michigan. 1996.

Lin Hong, Anil Jain, Sharathcha Pankanti_, Ruud Bolle. "Fingeprint Enhancement”. Pattern Recognition and Image Processing Laboratory Department of Computer Science Michigan State University. Michigan. 1996.

Minutix. “Minutia Based VS Pattren Based Fingerprint Identification Whitepaper”. Minutix. Corp 2003. 
Shivang Patel dan Jaap de Haan. "Fingerprint Verification System”. www.sourceforge.net. 2002

Zhang Weiwei, Wang Sen, Wang Yangsheng. "Structure Matching Algorithm Of Fingerprint Minutiae Based On Core Point". National Laboratory of Pattern Recognition-Institute of Automation - Chinese Academy of Sciences- Beijing. Beijing. 2003. 